\title{
DUAS FACETAS DA MORTE EM AUGUSTO DOS ANJOS
}

\section{TWO FACETS OF DEATH IN AUGUSTO DOS ANJOS}

\author{
Recebido: 13/05/2020 | Aprovado: 04/06/2020 | Publicado: 10/07/2020 \\ DOI: https://doi.org/10.18817/rlj.v4i1.2230
}

\begin{abstract}
Francine Fernandes Weiss Ricieri ${ }^{1}$ Orcid ID: https://orcid.org/0000-0002-4541-3090

Maristela Barboza ${ }^{2}$

Orcid ID: https://orcid.org/0000-0002-6140-0046
\end{abstract}

\begin{abstract}
Resumo: Inicialmente esquecida pela crítica, a poética de Augusto dos Anjos apresenta diversas facetas que constituem sua singularidade. Antes consideradas como um ponto negativo de sua obra, as peculiaridades da poesia augustiana são objeto de numerosos escritos acadêmicos desde os anos 50. Atualmente, ainda existem temas a serem explorados com maior profundidade. A presença de elementos do cristianismo é um desses tópicos. Por isso, este artigo busca refletir sobre a espiritualidade cristã no poeta do Eu por meio da análise comparada de dois sonetos dedicados à morte do pai do poeta. Os poemas possuem representações diferentes da morte e ao compará-las, delimitaremos duas manifestações da espiritualidade cristã associadas a elas.
\end{abstract}

Palavras-chave: Augusto dos Anjos. Literatura Brasileira. Morte. Cristianismo

Abstract: Initialy forgotten by the critics, Augusto dos Anjos's poetry presents several facets that make it unique. The parcularities once mentioned as a negative point of his work, are the subject of numerous academic papers since the 50's. Currently, there are still themes waiting to be explored in greater depth. The presence of elements of Christianity is one of those topics. Therefore, this paper seeks to reflect on Christian spirituality in poet through the comparative analysis of two sonnets dedicated to the death of the poet's father. The poems have different representations of death and two manifestations of the Christian spirituality related to them can be descrideb when they are compared.

Keywords: Augusto dos Anjos. Brazilian literature. Death. Christianity

Em 6 junho de 1912, Eu saía da editora, primeiro livro de poemas organizado e escrito por Augusto dos Anjos. O paraibano, que já estava familiarizado com a publicação de poemas em jornais desde jovem, passou das páginas de periódicos às do livro e financiou, com auxílio do irmão, mil exemplares da obra - como informa Raimundo Magalhães Jr. (1977) em Poesia e vida de Augusto dos Anjos.

${ }^{1}$ Licenciada em Letras pela Universidade Estadual de Londrina (1988), mestrado em Teoria Literária e Literatura Comparada pela Universidade Estadual Paulista Júlio de Mesquita Filho / UNESP (1996), doutora em Teoria e História Literária na área de Literatura Brasileira pela Universidade Estadual de Campinas / UNICAMP (2001), pós-doutora em Literatura Brasileira pela UNICAMP (FAPESP) e pós-doutora em tradução pela USP (2018). E-mail: francinericieri@gmail.com

${ }^{2}$ Graduada em Letras pela Universidade Federal de São Paulo. E-mail: marih_pmait@hotmail.com 
A recepção inicial, ainda no mês de lançamento, manifestou-se em resenhas na seção literária de gazetas ao redor do país. Conforme Magalhães Jr. (1977), a crítica de Oscar Lopes n'O País foi uma das primeiras a serem publicadas e apresenta considerações que se mostraram recorrentes neste momento inicial da fortuna crítica de Eu. Lopes elogia o caráter singular da lira augustiana, enfatizando seu teor bizarro e musical, e prevê que o livro provocaria estranheza nos leitores. Em seu texto, Lopes opina:

Algumas das composições são perfeitamente estranhas e caracterizadas por um evidente descaso por tudo quanto constitui a moeda corrente nas letras de nossa terra. Entretanto, passada a primeira impressão, o leitor verifica que dentro daquelas páginas palpita um espírito original [...] (MAGALHÃES JR, 1977, p. 254, grifos meus)

Euricles de Matos, em sua resenha em A Tribuna, a 13 de junho, enfatizou o caráter de novidade do livro e sua estranheza. $O$ texto resume-se a um comentário apologético e superficial. A contribuição de Nazareth Meneses, a 14 de julho, na Gazeta de Notícias, conta com uma opinião mais definida. Meneses inicia apontando a falta de beleza da poesia científica e sua presença passageira para argumentar que estaria na poesia lírica a beleza, a arte e a vibração. Para ele, poemas como "O Morcego", em Eu, conteriam esses traços. Mas os elogios carregam uma significativa ressalva:

Infelizmente as demais poesias do poeta não imitam essa sonoridade, envolvendo a pureza filosófica de uma ideia tão justamente elevada e frisante. Nota-se em todas as páginas deste volume a preocupação constante da tecnologia. Os versos do Sr. Augusto dos Anjos perdem, por isso, grande parte do encanto que a forma lhe empresta. (MAGALHÃES JR ,1977, p. 257,grifos meus)

Magalhães Jr. (1977) informa que Meneses cita trechos que ilustrariam sua afirmação e conclui:

Não citamos mais. Todo o livro está cheio de ideias e comparações. O poeta é moço ainda e tem talento bastante para abandonar essa poesia técnica, muito imprópria e muito postiça, e atirar-se a outros gêneros em que possa mais belamente florir o seu estro.(MAGALHÃES JR., 1977, p. 257 , grifos meus) 
Os apontamentos de Meneses repetem-se com maior intensidade no comentário escrito por Osório Duque Estrada. Seu parecer contém elogios, mas também conta com contundentes restrições: "Nove décimos da produção contida no volume não passam de extravagâncias e de exotismos condenáveis" (MAGALHÃES JR.,1977, p. 258).

Magalhães Jr. (1977) cita alguns outros escritos que formam a recepção inicial de Eu e, ao lê-los, torna-se notável a semelhança entre os vereditos. De maneira geral, os pareceristas reconhecem a singularidade de Eu e anunciam sua "ruidosa" chegada. Mas, para eles, os elementos que tornam a obra singular vocabulário científico, as metáforas inesperadas, referências a diversas correntes científicas e filosóficas, etc. - são indesejáveis. O vocabulário augustiano, por exemplo, uma das maiores especificidades de suas composições, é tido pela crítica primeva como prejudicial, um artefato extravagante que atrapalha aquele que deseja observar os poemas tidos como bons. Trata-se uma recepção crítica centrada no "apesar de", no "entretanto".

Nesse contexto, o autor de Eu seria considerado como um jovem que precisaria aprender a cultivar os aspectos que constituiriam "a moeda corrente nas letras" (MAGALHÃES JR., 1977, p. 254) e livrar-se do resto. Assim, em um movimento contra a diferença e a singularidade (as especificidades de Eu que o tornam único e que o afastam do cenário literário), a lira do poeta deveria amadurecer a fim de adequar-se ao cânone do período. Francisco Foot Hardman (2007), em "Augusto dos Anjos e o anti-tropicalismo", resume essa fase da recepção, que por ser pouco expressiva e numerosa não costuma ser explorada nos escritos que revisam a fortuna crítica augustiana, da seguinte forma:

[...] Eu [...] havia sido recebido pelos críticos com indiferença, ou no máximo certa indulgência ante o estranhamento que aqueles versos podiam provocar. A hegemonia estética e social dos valores parnasianos, naquele momento, rejeitava qualquer proposta que fugisse a seus cânones formais e temáticos, como eivada de 'mau gosto'. (HARDMAN, 2007, p.100)

A crítica permaneceu escassa e com o mesmo tom e, rapidamente, 0 breve frisson causado pela novidade cessou. No ano de 1914, data da morte do 
poeta, os exemplares ainda não haviam sido vendidos por completo. $O$ falecimento do artista gerou algumas publicações sobre $E u$ - como as feitas por amigos do poeta que exaltavam a qualidade de sua obra, através de carregado apologismo.

Esgotada a primeira edição, a obra caiu em esquecimento, permanecendo assim até o fim da década de 20. A segunda edição do livro, organizada por Órris Soares, em 1920, ganhou mais 48 poemas selecionados pelo organizador. Hardman (2007) expõe que, apesar do esforço, o livro não teve sorte diferente. Apenas na terceira edição do livro, em 1928, o literato ascendeu perante a recepção crítica.

Porém, como explora Henrique Duarte Neto (1997) em "A recepção crítica à obra de Augusto dos Anjos", a crítica dos anos 20 aos 40 do século XX, pode ser considerada imatura, pois a maioria dos escritos do período revelariam maior preocupação com aspectos bibliográficos do que estruturais do livro, abordagem que se manifesta em trabalhos nosológicos (muitos dos quais buscam ligações entre os poemas e a morte do poeta) e críticas centradas em elogios que estariam associados à análise superficial da obra.

Seria a partir dos anos 50 que a fortuna crítica iniciaria a exploração e a incorporação dos traços singulares e das especificidades augustianas por meio de reflexões mais profundas e maduras.

Atualmente, a produção acadêmica sobre a poética do $E u$ reconhece o estatuto de singularidade que revela a pluralidade de procedimentos, estilo e temas que marcam essa escrita.

Podemos destacar, a título de exemplo, os seguintes elementos: vocabulário científico, metáforas inesperadas, a temática da melancolia e doença, seu pessimismo, a influência do monismo de Haeckel e tantas outras marcas do cientificismo, a espiritualidade multifacetada, a estética do horrível, o diálogo com tendências ditas como parnasianas, simbolistas, pré-modernistas, decadentistas, cientificistas e expressionistas. Após mais de 100 anos de sua publicação, Eu ainda oferece diferentes vertentes a serem exploradas por pesquisadores.

Uma das temáticas mais proeminentes na fortuna crítica do paraibano é a morte. A decomposição, a podridão, a melancolia e o pessimismo associados ao óbito são presenças frequentes nos poemas augustianos. Esse traço pode ser 
abordado em associação a outros temas que também são latentes em suas produções. Como, por exemplo, as ideias ligadas à Escola de Recife ${ }^{3}$ e outros itens que não protagonizam tantas pesquisas, a saber, a espiritualidade cristã na obra augustiana.

Nesse contexto, o presente artigo visa dialogar com essa temática, propondo a hipótese de existência de duas facetas da espiritualidade de matriz cristã na poesia de Augusto dos Anjos. Com o objetivo de traçar um pequeno quadro dessas manifestações poéticas, realizaremos uma análise comparativa de dois poemas que integram a trilogia chamada "Sonetos". Os textos que compõem o exercício analítico são: "II" e "III". A fim de compreender como a espiritualidade cristã seria desenvolvida nas composições, adotaremos como foco a forma como representam a morte. Transcrevemos abaixo os poemas referidos.

II

A meu Pai morto

Madrugada de Treze de Janeiro.

Rezo, sonhando, o ofício da agonia.

Meu Pai nessa hora junto a mim morria

Sem um gemido, assim como um cordeiro!

E eu nem Ihe ouvi o alento derradeiro!

Quando acordei, cuidei que ele dormia,

E disse à minha Mãe que me dizia:

"Acorda-o!" deixa-o, Mãe, dormir primeiro!

E saí para ver a Natureza!

Em tudo o mesmo abismo de beleza,

Nem uma névoa no estrelado véu...

Mas pareceu-me, entre as estrelas flóreas, Como Elias, num carro azul de glórias,

Ver a alma de meu Pai subindo ao Céu! (DOS ANJOS, 2004, p. 269-270)

III

Podre meu Pai! A morte o olhar Ihe vidra.

Em seus lábios que os meus lábios osculam Microrganismos fúnebres pululam

Numa fermentação gorda de cidra.

3 Conforme aponta Candeias (2015) em Augusto dos Anjos: um moderno entre os "ismos", a Escola de Recife é o termo relacionado a um grupo de intelectuais em atuação na década de 1870 e que, tendo Tobias Barreto como figura de liderança, disseminavam ideias ligadas às correntes de pensamento positivista. Haeckel, Spencer, Darwin, Kant e Comte são exemplos de pensadores cujas ideias foram introduzidas pelo grupo. 
Duras leis as que os homens e a hórrida hidra

A uma só lei biológica vinculam,

E a marcha das moléculas regulam,

Com a invariabilidade da clepsidra!...

Podre meu Pai! E a mão que enchi de beijos

Roída toda de bichos, como os queijos

Sobre a mesa de orgíacos festins!..

Amo meu Pai na atômica desordem

Entre as bocas necrófagas que o mordem

$E$ a terra infecta que lhe cobre os rins!

(DOS ANJOS, 2004, p. 268)

Esses sonetos foram escritos pelo poeta em decorrência da doença e morte de seu pai, Dr. Alexandre Rodrigues dos Anjos. A produção "II" transporta o leitor ao momento exato da morte do pai já no primeiro verso. A precisão temporal é importante para construir a tensão emocional que domina o sujeito lírico. $O$ segundo verso, "Rezo, sonhando, o ofício da agonia" (DOS ANJOS, 2004, p. 268), marca o início do desassossego. Nele, devido às circunstâncias do processo de morte paterna, o ato de rezar transformar-se em uma atividade laboriosa e desagradável. O ofício da agonia é seguido pela morte do pai próximo ao filho. Morte que ocorreu sem gritos, sem nenhum suspiro, como a de um cordeiro.

A reza e a comparação entre a morte paterna e a de um cordeiro evocariam simbologias cristãs. Em diversas passagens da bíblia, Jesus Cristo tem sua figura associada a esse animal, como agnus dei. Um exemplo de tal comparação encontra-se no seguinte trecho de Isaías 53:7:

Ele foi oprimido e afligido, mas não abriu a sua boca; como um cordeiro foi levado ao matadouro, e como a ovelha muda perante os seus tosquiadores, assim ele não abriu a sua boca. (BÍBLIA SAGRADA, 1999, p. 499).

Podemos estabelecer um diálogo entre a passagem bíblica transcrita e os versos "Meu Pai nessa hora junto a mim morria/ Sem um gemido, assim como um cordeiro!" (DOS ANJOS, 2004, p. 269-270), já que ambos descrevem uma morte tranquila, precedida de grande sofrimento. $O$ poeta compararia a doença que torturou seu pai à violência imposta ao cordeiro de Deus antes de sua crucificação. 
Mesmo acometidos por dores, Jesus e a figura paterna não exteriorizam o sofrimento, permanecendo em silêncio.

Após essa metáfora bíblica, temos a comparação da morte com o sono. Através dela, a aflição do primeiro parágrafo cederia lugar à calma. A voz poética, não ciente da morte do pai - diz pensar que ele dormia "Quando acordei, cuidei que ele dormia" (DOS ANJOS, 2004, p. 269-270) - impede que sua mãe acorde o pai, deixando-o, assim, no sono da morte.

Sem dar conta do falecimento, o eu lírico se dirige para fora da casa e busca entrar em contato com a natureza. Esse movimento de busca remeteria ao expediente bíblico de comparação entre Deus e a Natureza. Tal recurso seria utilizado para explicar os atributos metafísicos de Deus através de suas contrapartes indicadas nos elementos naturais criados pela divindade. Um exemplo disso pode ser visto em versículos como Romanos 1: 20:

Porque os atributos invisíveis de Deus, assim o seu eterno poder, como também a sua própria divindade, claramente se reconhecem, desde o princípio do mundo, sendo percebidos por meio das coisas que foram criadas [...] (BÍBLIA SAGRADA, 1999, p. 124).

Dessa forma, podemos interpretar que o filho, devido à iminente perda de seu pai, recorreria a Deus, por intermédio da aproximação com a natureza. Como resposta à procura, o eu lírico depara-se com um abismo de beleza e com um céu límpido e estrelado. Porém, uma imagem parece povoar o céu: a alma do pai em ascensão. Aqui teríamos a segunda metáfora bíblica, a clara comparação entre o pai representado no poema e Elias.

Elias foi o primeiro profeta enviado por Deus a Israel e Judá e teria sido arrebatado por Deus, tendo assim ascendido ao reino dos céus sem morrer. $O$ arrebatamento ocorreu enquanto o profeta conversava com Eliseu, conforme 2 Reis 2: 9-11:

Indo eles andando e falando, eis que um carro de fogo, os separou um do outro; e Elias subiu ao céu num redemoinho. O que vendo Eliseu, clamou: Meu pai, meu pai, carros de Israel e seus cavaleiros! [...] (BÍBLIA SAGRADA, 1999, p. 263). 
Na comparação, o eu lírico identifica-se com a figura de Eliseu que vê seu mestre sendo levado por forças divinas. O clamor surpreso do sucessor de Elias, "Meu pai, meu pai!", muito aparenta-se com a surpresa da voz lírica, ao pensar vislumbrar a alma de seu pai subindo ao céu.

No soneto como um todo existiria um crescente de calma, tranquilidade e beleza. Nos primeiros quartetos, há a aflição do filho durante o momento da morte do pai. Porém, nos tercetos tem-se a calma ascendente. A tranquilidade se manifesta por intermédio do contato da voz lírica com a natureza e da visão da alma paterna ascendendo aos céus.

Acompanhando essa atmosfera de tranquilidade, percebemos que as imagens construídas pelo poeta se mostram iluminadas, com destaque à figura das estrelas e da cor azul. Além disso, constatamos a ausência do que Manuel Cavalcanti Proença (1976) chama de densidade semântica, em "O artesanato em Augusto dos Anjos". Proença (1976) explica que a densidade poderia ser alcançada por intermédio de diversos recursos, mas que o principal deles seria o uso de termos científicos. Isso ocorreria pois tais vocábulos carregariam em si uma pureza musical derivada da incompreensão que pode residir nos leitores. Os termos científicos também seriam dotados de um caráter de súmula conceitual, de precisão e concisão. Esses atributos permitiriam que fosse atingida uma densidade semântica via vocabulário científico.

Nos versos afastados do cientificismo, o conceito de alma seria dotado de natureza imortal e imaterial, assumindo a existência metafísica. Ainda destacamos que a alma paterna parece transcender, já que ascende ao reino dos céus em uma manifestação poética que muito se adequa à lógica e doutrina cristã.

Essa adequação se dá na medida em que, a ideia de alma utilizada é compatível com a definição de alma implicada no modelo criacionista. Segundo David. F. Wright, em seu verbete "Alma, origem" para o Novo dicionário de Teologia (2009), essa concepção goza de maior difusão e adeptos, estando entre eles a doutrina oficial do catolicismo romano e uma parcela de teólogos reformados. De acordo com Wright (2009), o Criacionismo afirmaria que a alma é criada ex nihilo e dada aos humanos por Deus. Além disso, essa doutrina estabeleceria um dualismo e uma dicotomia entre: "a alma (e.g imortal, imaterial e indivisível) e o corpo" (WRIGHT, 2009, p. 52). Trata-se das mesmas 
características passíveis de serem atribuídas à alma através do soneto de Augusto dos Anjos, ou seja, a visão de alma no objeto de análise seria de cunho criacionista e, por consequência, cristão.

A concepção da alma que se manifesta através da tônica de serenidade da composição culminaria em uma abordagem perante a morte que mitiga seus aspectos vis e materiais, para focar no seu caráter enquanto "acontecimento metafísico". Dessa maneira, a morte é tida como uma ocorrência que resulta na ascensão espiritual, na vida espiritual após a morte. Tal ascensão mostra-se através da sequência: morte do pai (primeira estrofe) > alma paterna ascendendo ao reino dos céus.

Essa concepção da morte associa-se à doutrina cristã, pois, conforme apontado por M. J. Harris, no verbete "Morte" no Novo dicionário de Teologia (2009), a morte física é vista como uma força destrutiva por ser responsável pelo fim da existência da corporeidade da habitação temporária que é o corpo humano. Porém, de acordo com Harris (2009), a morte corporal teria aspectos positivos porque: reafirma que foi Deus quem deu o sopro da vida; marca o descanso do trabalho eterno; possibilita a entrega do espírito às mãos divinas e a passagem de uma vida terrena para estar na presença do criador.

De modo ao proposto na definição teológica, no soneto, a morte do pai é tratada pelo eu lírico como um acontecimento doloroso que o faz rezar em agonia, mas que apresentaria uma contraparte positiva: a ascensão aos céus e a presença de Deus. Existiria, então, uma adequação à lógica cristã e aos seus pressupostos acerca da morte física.

Márcia Peters Sabino (2005), em "A questão da religiosidade em Augusto dos Anjos", ensaio no qual versa sobre como a influência do positivismo resulta no combate à religião na poesia do paraibano, durante sua análise de "Sonetos", aponta que todos os membros da trilogia seriam um exemplo de refutação da religião cristã. Nos comentários específicos à parte II da trilogia, a autora destaca, para corroborar sua hipótese, que o vocábulo pai com letra maiúscula operaria a substituição heterodoxa do pai divino pelo pai biológico. Além disso, o poeta compararia a morte de Elias à de seu pai, apropriando-se de "uma imagem bíblica para se referir a um acontecimento humano e pessoal" (SABINO, 2005, p. 12). 
Devido a esses indícios, a autora entende que "Algum crítico mais impaciente poderia adiantar-se e afirmar que neste poema está presente a religiosidade de Augusto dos Anjos." (SABINO, 2005, p. 11). Concordamos com a autora, mas com ressalvas.

Aceitamos que a aproximação de uma imagem divina a um ser mundano caracteriza uma apropriação heterodoxa da simbologia cristã, porém essa comparação não seria capaz de negar toda a espiritualidade dessa composição, visto que a concepção de morte estaria fortemente de acordo com a espiritualidade cristã. Entendemos que essa conformidade está bem delimitada na manifestação poética da morte e da alma e menos delimitada nas comparações envolvendo figuras bíblicas. Por esse motivo, optamos pelo recorte específico direcionado à imagem da morte na análise comparativa entre "II" e "III".

Portanto, defendemos que o soneto analisado se apresenta como uma manifestação poética do cristianismo que respeita, não completamente, porém de maneira pronunciada, a lógica cristã. Mesmo que a comparação com Jesus e Elias possa ser interpretada como herética, não vemos nela uma reinvenção ou paródia desses símbolos e da lógica cristã de maneira acentuada.

Esse respeito aos valores e lógica cristã e à utilização de termos e símbolos do cristianismo em consonância com seu sentido original - respeitando o caráter metafísico, como ocorre com a morte e a alma em "II" - configuraria uma das facetas da manifestação poética da espiritualidade cristã na poesia de Augusto dos Anjos. A ela daremos o nome de cristianismo metafísico e acreditamos que a mesma se oporia à outra manifestação poética que inverteria a lógica cristã, reconfigurando-a. Para exemplificá-la, analisaremos a parte III da trilogia.

O poema inicia-se com um lamento que indica o estado corporal do pai após seu falecimento. O eu lírico reporta a situação do corpo: olhos vítreos e lábios que agora servem de locação para microrganismos nascerem. Os mesmos lábios que recebiam beijos do filho, agora são mutilados e consumidos por seres ínfimos devido às duras leis que são capazes de unir seres tão díspares quanto o homem e a hidra ${ }^{4}$ a um único destino: a morte. 
No primeiro terceto, o eu lírico prossegue a listar as transformações operadas por pequenos organismos no corpo do pai. O leitor toma conhecimento de que as mãos outrora beijadas agora assemelham-se a queijos esburacados, pois servirão de banquete aos bichos. No terceto final, o eu lírico declara seu carinho pelo pai. $\mathrm{O}$ amor filial permanece atuante, mesmo em face da atômica desordem da devoração protagonizada pelos bichos.

Na parte III da trilogia publicada em Eu, diferentemente da parte II, temos densidade semântica, nos termos de Proença (1976). Os vocábulos e as temáticas biológico-científicos conferem expressividade e profundidade aos versos.

As imagens alcançadas por esses vocábulos não são iluminadas, mas remetem à sombria corrupção do corpo após a morte, uma vez que os versos não são dedicados ao recém-morto (como na parte com a epígrafe "A meu pai morto"), mas ao pai que já está enterrado há um relativo período de tempo. O que indica ao leitor a distância temporal entre o corpo do pai em "II" e em "III" é a dinâmica da mastigação presente no último poema. A atmosfera de mastigação é evocada pelo vocabulário empregado no texto.

Transcrevemo-lo novamente, destacando os vocábulos relacionados ao ato de devorar, mastigar e alimentar, a fim de ilustrar como eles são representativos e dominantes:

III

Podre meu Pai! A morte o olhar lhe vidra.

Em seus lábios que os meus lábios osculam

Microrganismos fúnebres pululam

Numa fermentação gorda de cidra.

Duras leis as que os homens e a hórrida hidra

A uma só lei biológica vinculam,

E a marcha das moléculas regulam,

Com a invariabilidade da clepsidra!...

Podre meu Pai! E a mão que enchi de beijos

Roída toda de bichos, como os queijos

Sobre a mesa de orgíacos festins!...

Amo meu Pai na atômica desordem

Entre as bocas necrófagas que o mordem

$E$ a terra infecta que lhe cobre os rins!

(DOS ANJOS, 2004, p. 268, grifos meus) 
Acreditamos que essa temática de devoração dialoga com um elemento da obra de Augusto dos Anjos que Lúcia Helena, em A cosmo-agonia de Augusto dos Anjos (1977), chama de fagismo. Para a autora, Eu poderia ser interpretado como um único e muito repensado poema que configuraria a cosmogonia do poeta. Essa criação teria três núcleos temáticos: o transformismo, a intuição monista e o fagismo. Esse último é definido da seguinte forma:

\begin{abstract}
O fagismo - em suas múltiplas manifestações: a glutoneria, o antropofagismo, o verme, o desvirginar do labirinto do velho e metafísico - libera para o texto de Augusto dos Anjos o corte verticalizante em que se lêem criticamente as leis universais do transformismo e as cadeias causais do evolucionismo de espécie. (HELENA, 1977, p. 57).
\end{abstract}

Essa citação contém muitas informações e mostra-se muito rica para nossa análise. Helena (1977) lista algumas das manifestações do fagismo, sendo que a maioria, dentre as listadas pela autora no excerto, pode ser encontrada em "III". A glutoneria manifesta-se através de vocábulos e construções como: "fermentação gorda de cidra", "queijos", "Sobre a mesa de orgíacos festins", "bocas necrófagas que o mordem" e "roída". A imagem total que o emprego desse léxico de mastigação gera também reflete o fagismo via glutoneria, pois a imagem desenvolvida é a do corpo podre do pai do eu lírico virando um banquete aos bichos que agora o devoram. A figura do verme devorador ilustra o fagismo por meio de termos correlatos como "bichos" e a metonímia "bocas necrófagas".

Interpretamos que o "desvirginar do labirinto do velho e metafísico" estaria ligado a uma dissociação ou crítica às ideias metafísicas. A crítica no soneto estaria manifestada através do abandono da concepção metafísica de morte (aquela que relaciona esse acontecimento à ascensão da alma ou do espírito). Portanto, a concepção de morte desligada de qualquer característica metafísica, mística ou transcendental ilustraria o "desvirginar do labirinto do velho e metafísico".

Ainda sobre a manifestação poética da morte nessa composição, podemos destacar que ela é resumida à decomposição e corrupção do corpo terreno. Não parece haver indícios de uma alma que transcende e se desprende 
do corpo mortal para realizar uma ascensão rumo ao reino dos céus - como ocorre em "Il". A morte resulta apenas na devoração operada pelos vermes e seres do fundo da cadeia evolutiva.

Entendemos que essa forma de representar a morte estaria relacionada ao conceito de "descensão". Esse termo foi cunhado por Casemiro (2015) em Augusto dos Anjos ou incipit tragoedia: as máscaras de Dioniso na poesia de Eu e diz respeito a um movimento descendente que seria encontrado na poética augustina. Esse elemento é destacado por Casemiro durante vários momentos de sua tese. Um exemplo deles está no trecho abaixo, que parece elucidar o conceito:

Um dos mais importantes movimentos da obra $E u$, e que facilmente podemos diagnosticar nesse poema [O Deus-Verme], é aquele a que denomino descensão, ou seja, há na poesia de Augusto dos Anjos o predomínio do sentido descensional, para o qual aponta a tão conhecida força de decomposição. (CASEMIRO, 2015, p. 93, grifo do autor)

A "descensão", nos termos de Casemiro (2015), operaria a inversão do sentido ascendente da evolução e da religião. No soneto, ela pode ser apontada através da orientação (de cima para baixo) das imagens poéticas às quais ele se reporta.

Comecemos pela manifestação de "descensão" através das partes do corpo. O fio condutor das estrofes parece ser a deterioração do corpo paterno pela decomposição operada por bichos e microrganismos. Esse processo segue uma verticalidade descendente contada através dos membros e órgãos que são afetados. O percurso se inicia na cabeça, com os olhos que são deteriorados, pois o brilho e a vivacidade que outrora possuíam foram tomados pela morte. Descendo da linha dos olhos para a boca, o eu lírico se dedica a retomar o estado anterior dos lábios do pai. Antes eles recebiam beijos, mas, agora, são o lar da multiplicação rápida e abundante de microrganismos. Após versar sobre os lábios, a voz lírica faz um movimento para baixo e segue descrevendo as mãos do cadáver. A mão, que assim como os lábios era beijada, apresenta buracos semelhantes aos queijos. Por fim, o último movimento descendente versa sobre os rins que são cobertos pela terra imunda. Encontramos nesse conjunto de 
versos uma "descensão" anatômica que acompanha o trabalho da morte e de seus parceiros: os operários das ruínas.

O segundo exemplo de "descensão" listado abrange e é alçando por intermédio do soneto como um todo. Trata-se da transformação hierárquica da posição alta gozada pelo homem na cadeia evolutiva e também na cadeia alimentar. O pai do eu lírico deixa de ser o homem que se serve da cidra, dos queijos e que pode participar de orgíacos festins para tornar-se o banquete dos seres inferiores que se nutrem de matéria decomposta. Paralelamente, o topo da cadeia alimentar serve de alimento aos decompositores - microrganismos e outros seres que se alimentam de cadáveres.

Outra manifestação poética da "descensão" encontra-se nos versos: "E a marcha das moléculas regulam/ Com a invariabilidade da clepsidra..." (DOS ANJOS, 2004, p. 268) e "Amo meu pai na atômica desordem" (DOS ANJOS, 2004, p. 268). Nesses trechos haveria a passagem de um estado de extrema ordem para a desordem.

Pensemos no primeiro estado: no quadro, para resumi-lo, destacamos apenas dois versos, mas a ideia de ordem é alcançada e estende-se pela segunda estrofe inteira. O leitor percebe, durante a leitura desse quarteto, um conjunto de palavras e construções cujo léxico remete à ordem: "duras leis", "lei biológica", "marcha das moléculas regulam", "com a invariabilidade da clepsidra". O poeta utiliza-se desses termos para versar sobre a inflexibilidade das "duras leis" que são capazes de submeter seres tão díspares quanto o homem e a hidra (seja ela o ser mitológico, seja o minúsculo invertebrado) a uma única lei da biologia: a morte. Cabe destacar que essas "duras leis" também regulam a marcha das moléculas de maneira invariável, tal qual a passagem do tempo por um relógio d'água. Assim sendo, a estrofe apresenta leis incontornáveis e invariáveis, dado que a morte virá para todos e as leis que a comandam são da ordem do invariável, além de regerem o andar organizado das moléculas rumo ao cumprimento dessas leis biológicas.

Mas a atmosfera de ordem parece se dissipar logo após o cumprimento da lei biológica da morte, porque o corpo sem vida configura o segundo estado: a atômica desordem. Representamos esse estado através do verso "Amo meu pai na atômica desordem" (DOS ANJOS, 2004, p. 268), pois ele funciona como uma 
súmula da situação em que o corpo paterno se encontra. Porém, a ideia de desordem após a morte permeia todas as estrofes, com exceção do quarteto analisado acima.

Servindo-nos da possibilidade de leitura que interpreta o termo "hórrida hidra" como referência ao pequeno invertebrado de água doce, identificamos outro exemplo de "descensão" no fato de que a morte rebaixa o homem, já que o coloca em um estado de igualdade com a hidra.

Por último, retomando o comentário analítico de Sabino (2005) acerca do uso da palavra "Pai" com letra maiúscula, exemplificaremos mais um caso de "descensão". Concordamos com a autora que essa comparação entre a figura bíblica de Deus e o pai do eu lírico representaria uma refutação do cristianismo. Isso ocorreria porque, ao utilizar a letra maiúscula, o poeta faz com que a figura paterna tome o lugar da divina. Entendemos que esse posicionamento gera 0 movimento de queda da posição hierárquica de Deus, visto que sua natureza pura e metafísica é rebaixada ao nível de um cadáver decomposto. O pai do eu lírico viraria "deus humano, corpóreo, concreto" (SABINO, 2005, p. 12). Essa imagem nos permite pensar em como o cristianismo é representado por meio dessa comparação.

Deus, figura central do cristianismo, dotado de uma natureza metafísica, seria comparado a um cadáver em plena decomposição. Essa aproximação gera uma substituição do metafísico pelo o que é mundano, pelo o que é da terra e, por consequência, telúrico. Essa forma de se apropriar do cristianismo, reinventandoo e parodiando-o configuraria o que chamaremos de "cristianismo telúrico". O termo é utilizado por Casemiro (2015) durante a análise que realiza de "O DeusVerme". Nela, o autor explora a figura do Cristo-Verme que seria uma entidade física, paródica e telúrica que operaria uma "descensão", oposta à ascensão cristã, e afirma que no objeto analisado "pode-se perceber uma apropriação, uma irônica reinvenção (que inscreve uma reorientação) do cristianismo" (CASEMIRO, 2015, p. 89). A reorientação está ligada à "descensão", que pode ser entendida como uma das marcas desse cristianismo telúrico augustiano. Para elucidar essa participação do movimento descensional, transcrevemos o seguinte trecho: 
A descensão, nesse poema, parodiando a ascensão do Cristo, é mais um elemento a revelar o método do devoramento paródico como grande estratégia dessa contrapoesia. Vale ressaltar que, nesse poema, assim como o eu lírico aproxima os termos cristãos dos termos científicos (ambos participantes do paradigma ascensional, na cultura do século $X I X)$, ele também, pela descensão paródica, devora o cristianismo (não metafísico, mas físico porque telúrico) [...] (CASEMIRO, 2015, p. 94).

Nesse momento de sua tese e em outros trechos, o autor expõe sua visão de como o cristianismo se mostraria na obra augustiana. Essa espiritualidade não seria metafísica, mas física, paródica, telúrica e às avessas. Nesse artigo, ao tratar do cristianismo telúrico, estamos dialogando estreitamente e nos servindo da percepção de Casemiro sobre como o cristianismo augustiano pode se manifestar.

Acreditamos que esse cristianismo, diferentemente do metafísico, encontra-se em "III", porque nele há uma apropriação da figura cristã de Deus para reinventá-la e parodiá-la, pois ela é transformada em uma entidade física, telúrica e putrefata. Haveria uma inversão e "descensão" dos valores cristãos que atribuem a Deus um estatuto metafísico, a fim de criar uma divindade telúrica que seria o cadáver do pai do eu lírico.

A mesma substituição do caráter metafísico para o físico e da ascensão para a "descensão" ocorre com o conceito de morte. Em "Il", analisado anteriormente, a representação poética do cristianismo estava associada, apesar dos pontos problemáticos, ao respeito à lógica cristã e ligada a um sentido ascendente.

Em "III", a morte não tem caráter metafísico e não se relaciona à ascensão da alma ao reino dos céus. O falecimento não abriria margem para a ideia de alma - que não é citada em nenhum momento. A morte geraria, como destacado ao explorarmos o conceito de "descensão" e "fagismo", apenas fenômenos físicos como a devoração e decomposição do corpo. Nesse cenário tão telúrico e infecto, não nos parece plausível a inserção de pensamentos metafísicos como a ascensão da alma.

Em suma, no cotejo entre os textos, compreendemos que ambos compartilham da mesma temática central: a morte. Porém, em "Il" a morte desdobra-se em calma e beleza que dialogam com as imagens iluminadas construídas no poema. Já em "III", a morte associa-se à corrupção e à 
deterioração do corpo humano - que são representadas pela devoração do cadáver por bichos necrófagos.

Portanto, em "Il" é possível estabelecer relações de respeito à lógica cristã, pois a morte, nessa composição, configura-se como um acontecimento físico com contraparte metafísica. Essa última possibilita que o falecimento gere uma ascensão da alma que se adequaria à visão de morte da doutrina cristã. Consequentemente, essa manifestação poética da morte alinha-se ao que denominamos de cristianismo metafísico. Em contrapartida, em "III", a morte é reduzida a um episódio físico, sem conexão com uma visão metafísica e religiosa do mundo. A recusa da religiosidade e a comparação de uma divindade ao ser mundano filia-se ao cristianismo telúrico (conceito que busca agrupar as reflexões de Casemiro (2015) sobre o cristianismo na obra de Augusto dos Anjos).

Alinhar esses sonetos díspares, analisando-os através do prisma da representação da morte, permite-nos delimitar as diferenças entre as manifestações poéticas do cristianismo metafísico e telúrico. Assim, procuramos traçar um pequeno quadro ilustrativo do cristianismo nas composições de Augusto dos Anjos.

\section{Referências}

Bíblia Sagrada. Trad. João Ferreira de Almeida. São Paulo: Sociedade Bíblica do Brasil, 1999.

CANDEIAS, Daniel Levy. Augusto dos Anjos: um moderno entre os "ismos". 2015. 168 f. Tese (Doutorado em Teoria Literária e Literatura Comparada) Universidade de São Paulo, São Paulo, 2015.

CASEMIRO, Fábio Martinelli. Augusto dos Anjos ou incipit tragoedia: as máscaras Ide Dioniso na poesia de Eu. 2015. 182 f. Tese (Doutorado em Teoria e História Literária) - Universidade Estadual de Campinas, Campinas, 2015.

DUARTE NETO, Henrique. A recepção crítica à obra de Augusto dos Anjos. Anuário de Literatura, Florianópolis, p. 225-240, jan. 1997.

DOS ANJOS, Augusto. Obra completa. Organização de Alexei Bueno. Rio de Janeiro: Nova Aguilar, 2004.

HARRIS, M. J. "Morte". In: FERGUSON, Sinclair B., WRIGHT, David F. Novo Dicionário de Teologia. São Paulo: Hagnos, 2009. 
HELENA, Lúcia. A cosmo-agonia de Augusto dos Anjos. Rio de Janeiro: Tempo Brasileiro, 1977.

MAGALHÃES JR., Raimundo. Poesia e vida de Augusto dos Anjos. Rio de Janeiro, Civilização Brasileira, 1977.

PROENÇA, M. Cavalcanti. O artesanato em Augusto dos Anjos. In: PROENÇA, M. Cavalcanti. Augusto dos Anjos e outros ensaios. Rio de Janeiro/Brasília: Grifo/INL/MEC, 1973.

SABINO, Márcia Peters. A questão da religiosidade em Augusto dos Anjos. Letras e Letras, Uberlândia, v. 21, n, 2, p. 1-21, jul/dez. 2005.

WRIGHT, David, F. "Alma, origem". In: FERGUSON, Sinclair B., WRIGHT, David F. Novo Dicionário de Teologia. São Paulo: Hagnos, 2009. 